\title{
An ultrafast nickel-iron battery from strongly coupled inorganic nanoparticle/nanocarbon hybrid materials
}

\author{
Hailiang Wang ${ }^{1}$, Yongye Liang ${ }^{1}$, Ming Gong ${ }^{1}$, Yanguang Li1, Wesley Chang ${ }^{1}$, Tyler Mefford', Jigang Zhou², \\ Jian Wang ${ }^{2}$, Tom Regier ${ }^{2}$, Fei Wei ${ }^{3} \&$ Hongjie Dai ${ }^{1}$
}

Ultrafast rechargeable batteries made from low-cost and abundant electrode materials operating in safe aqueous electrolytes could be attractive for electrochemical energy storage. If both high specific power and energy are achieved, such batteries would be useful for power quality applications such as to assist propelling electric vehicles that require fast acceleration and intense braking. Here we develop a new type of $\mathrm{Ni}$-Fe battery by employing novel inorganic nanoparticle/graphitic nanocarbon (carbon nanotubes and graphene) hybrid materials as electrode materials. We successfully increase the charging and discharging rates by nearly 1,000-fold over traditional Ni-Fe batteries while attaining high energy density. The ultrafast $\mathrm{Ni}-\mathrm{Fe}$ battery can be charged in $\sim 2$ min and discharged within $30 \mathrm{~s}$ to deliver a specific energy of $120 \mathrm{Wh} \mathrm{kg}^{-1}$ and a specific power of $15 \mathrm{~kW} \mathrm{~kg}^{-1}$. These features suggest a new generation of $\mathrm{Ni}-\mathrm{Fe}$ batteries as novel devices for electrochemical energy storage.

\footnotetext{
${ }^{1}$ Department of Chemistry, Stanford University, Stanford, California 94305, USA. ${ }^{2}$ Canadian Light Source Inc., Saskatoon, Saskatchewan, Canada S7N 0X4.

${ }^{3}$ Department of Chemical Engineering, Tsinghua University, Beijing 100084, China. Correspondence and requests for materials should be addressed to H.D. (email: hdai@stanford.edu).
} 
U sing electricity, instead of internal combustion engines, to propel vehicles is an effective way of reducing greenhouse gas emission and consumption of non-renewable fossil fuels. Thus far, batteries have been considered the most suitable devices for powering hybrid electric vehicles and all-electric vehicles ${ }^{1-5}$. To meet the challenges facing battery powered vehicles, it is necessary to significantly increase the specific power output and energy capacity of batteries. It is also important to lower the cost and meet the stringent safety requirements of batteries for all-electric vehicles. These characteristics are also important for batteries in storing energy from electrical grids supported by intermittent energy sources such as solar, wind and hydropower. Although Li ion batteries are of high efficiency and energy density, they are expensive and could be unsafe because of the flammability of organic electrolytes and high reactivity of Li containing electrode materials ${ }^{6-8}$. It is worthwhile exploring other battery systems that could operate with materials of low cost in safe aqueous electrolytes.

The nickel-iron battery was invented by Waldemar Jungner and Thomas Edison in 1899-1902 and fully developed over the past century $^{9,10}$. With $\mathrm{NiO}(\mathrm{OH})$ as the cathode and $\mathrm{Fe}$ as the anode, a typical $\mathrm{Ni}-\mathrm{Fe}$ battery is able to deliver specific gravimetric energy of $\sim 30-50 \mathrm{Wh} \mathrm{kg}^{-1}$ and power of $\sim 3-50 \mathrm{~W} \mathrm{~kg}^{-1}$ (refs 9,10). With a long cycle life even under harsh conditions, the Ni-Fe battery is known to be a robust and durable power source that has been used for a long time ${ }^{10}$. Importantly, both $\mathrm{Ni}$ and $\mathrm{Fe}$ are abundant elements on earth and relatively nontoxic. Other than the drawback of low power and energy density relative to $\mathrm{Li}$ ion batteries, $\mathrm{Ni}-\mathrm{Fe}$ battery is highly desirable for renewable energy storage. It is interesting to revisit the century-old $\mathrm{Ni}-\mathrm{Fe}$ battery and address whether it is possible to significantly improve the specific capacity of $\mathrm{Ni}-\mathrm{Fe}$ batteries at high charging and discharging rates, aimed at modern hybrid electric vehicle and all-electric vehicle applications, such as to assist $\mathrm{Li}$ ion batteries during acceleration and regenerate braking energy, and grid applications such as load following and frequency regulation where fast response is needed.

Here we report a new generation of high-performance rechargeable ultrafast $\mathrm{Ni}-\mathrm{Fe}$ battery (ultra-Ni-Fe battery) capable of ultrafast operations for both charging and discharging enabled by using inorganic/carbon hybrid electrode materials, including $\mathrm{Ni}(\mathrm{OH})_{2}$ nanoplates grown on oxidized multi-wall carbon nanotubes
(MWNTs) as the cathode and $\mathrm{FeO}_{x}$ nanoparticles grown on reduced graphene oxide (GO) sheets as the anode (Fig. 1). Direct growth of electrochemically active inorganic nanomaterials on mildly oxidized nanocarbon materials affords desirable morphology, size and dispersion of the active materials ${ }^{11-13}$. It also allows for strong covalent coupling between inorganic nanocrystals and carbon, leading to rapid electron transfer from active materials to current collectors $^{12,14-16}$. Charged in $\sim 2$ min and discharged in less than $30 \mathrm{~s}$, our ultra-Ni-Fe cell based on such hybrid materials delivers a specific capacity of $115 \mathrm{mAhg}^{-1}$ based on the mass of the active materials, corresponding to an energy density $>120 \mathrm{Wh} \mathrm{kg}^{-1}$ and a power density $>15 \mathrm{~kW} \mathrm{~kg}^{-1}$. The rate capability of the ultra-Fe-Ni battery is higher than that of conventional $\mathrm{Ni}-\mathrm{Fe}$ batteries by nearly 1,000 times. At a high current density of $37 \mathrm{Ag}^{-1}$, the coulombic efficiency of our ultra-Ni-Fe cell is nearly $100 \%$. The chargedischarge cycling stability of our battery currently shows an $\sim 20 \%$ capacity decay over 800 cycles, which is an aspect requiring further improvement.

\section{Results}

$\mathrm{Ni}(\mathrm{OH})_{2} / \mathrm{MWNT}$ hybrid as cathode for ultra-Fe-Ni battery. The cathode of our ultra-Ni-Fe battery was consisted of a $\mathrm{Ni}(\mathrm{OH})_{2} /$ MWNT hybrid material, synthesized by nucleating and growing nanocrystals on oxidized MWNTs, similar to the synthesis of $\mathrm{Ni}(\mathrm{OH})_{2}$ on graphene sheets ${ }^{11,14,17}$. By evaluating pseudocapacitive charge storage of $\mathrm{Ni}(\mathrm{OH})_{2}$ nanocrystals supported on graphene sheets oxidized to various oxidation degrees, we found that the conductivity of the graphene sheets and their coupling with $\mathrm{Ni}(\mathrm{OH})_{2}$ nanocrystals were the most important factors in determining the specific capacity and rate capability of the $\mathrm{Ni}(\mathrm{OH})_{2}$ hybrid materials ${ }^{14}$. Here we employed oxidized MWNTs as novel substrates over graphene sheets for nucleating and growing $\mathrm{Ni}(\mathrm{OH})_{2}$ nanocrystals. We expect that whereas the functional groups on the oxidized outer walls of the MWNTs could interact with $\mathrm{Ni}^{2+}$ to initiate nucleation and growth of $\mathrm{Ni}(\mathrm{OH})_{2}$ nanocrystals, the intact inner walls of the MWNTs could serve as highly conducting wires ${ }^{18}$ to provide optimal electrical wiring of the $\mathrm{Ni}(\mathrm{OH})_{2}$ nanocrystals. The MWNTs used in this work were produced in a fluidized bed reactor that yields $\sim 500$ tons of MWNTs annually with high purity (>99.9\%) and low cost (material cost $\left.\sim \$ 10 \mathrm{~kg}^{-1}\right)^{19-22}$.
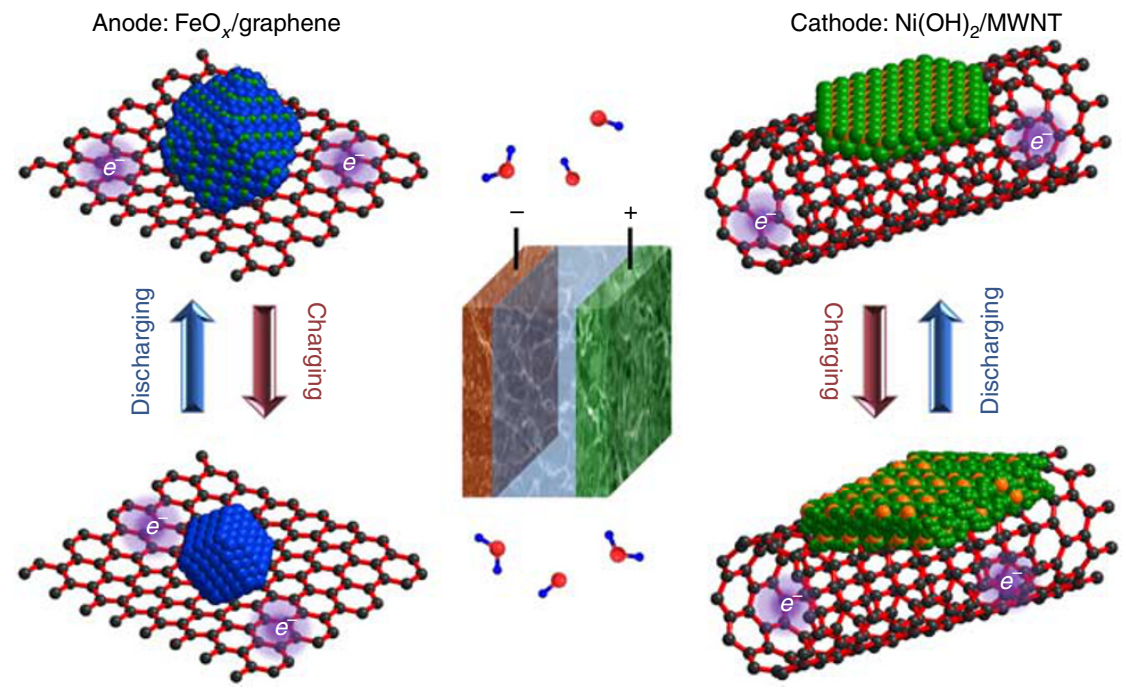

Figure 1 | Schematic drawing of the ultra-Ni-Fe battery made from inorganic/carbon hybrid materials. $\mathrm{A} \mathrm{Ni}(\mathrm{OH})_{2} / \mathrm{MWNT}$ hybrid was used as the cathode and $\mathrm{FeO} \mathrm{Fe}_{x} /$ graphene hybrid was used as the anode. $1 \mathrm{M}$ aqueous $\mathrm{KOH}$ solution was used as the electrolyte. On charging, $\mathrm{Ni}(\mathrm{OH})_{2} / \mathrm{MWNT}$ and $\mathrm{FeO}_{x}$ /graphene were converted to $\mathrm{NiOOH} / \mathrm{MWNT}$ and $\mathrm{Fe} /$ graphene, respectively. On discharging, $\mathrm{NiOOH} / \mathrm{MWNT}$ and Fe/graphene were converted back to $\mathrm{Ni}(\mathrm{OH})_{2} / \mathrm{MWNT}$ and $\mathrm{FeO}_{x} /$ graphene, respectively. 

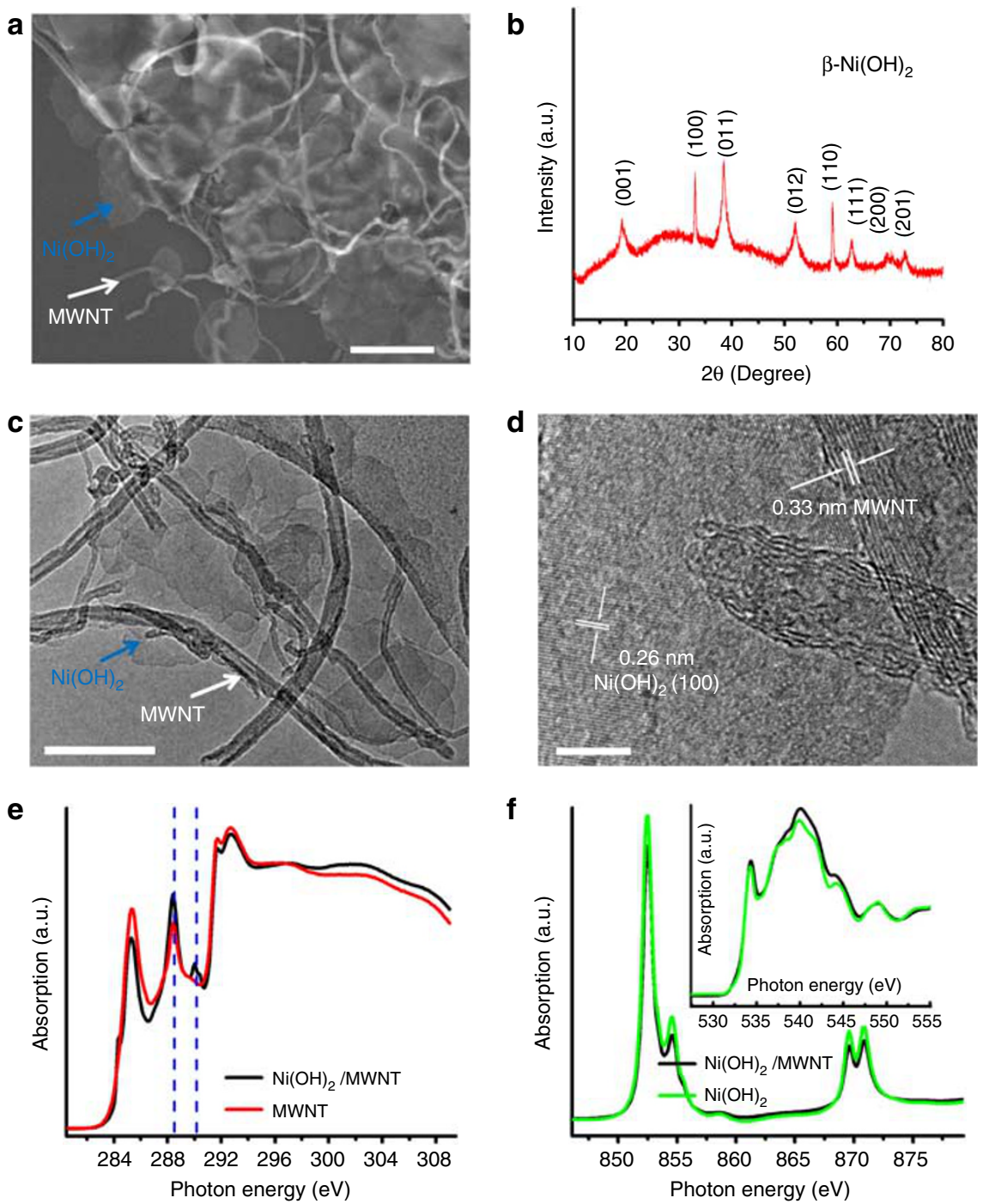

Figure 2 | Ni(OH) 2 /MWNT hybrid material. (a) An SEM image of $\mathrm{Ni}(\mathrm{OH})_{2}$ nanoplates grown on oxidized MWNTs. Scale bar, $200 \mathrm{~nm}$. (b) X-ray diffraction spectrum of a packed thick film of $\mathrm{Ni}(\mathrm{OH})_{2} / \mathrm{MWNT}$. (c) TEM image of $\mathrm{Ni}(\mathrm{OH})_{2}$ nanoplates grown on oxidized MWNTs. Scale bar, is $100 \mathrm{~nm}$. (d) A high-resolution TEM image of a Ni(OH) $)_{2}$ nanoplate attached to MWNTs. Scale bar, $5 \mathrm{~nm}$. (e) XANES spectra of the $\mathrm{Ni}(\mathrm{OH})_{2} / \mathrm{MWNT}$ hybrid and the MWNT control sample at carbon K-edge. The blue dashed lines mark the carboxyl $\pi^{\star}$ absorption at $288.5 \mathrm{eV}$ and the carbonate $\pi^{\star}$ absorption at $290.3 \mathrm{eV}$. (f) XANES spectra of the $\mathrm{Ni}(\mathrm{OH})_{2} / \mathrm{MWNT}$ hybrid and the $\mathrm{Ni}(\mathrm{OH})_{2}$ control sample at nickel L-edge. The inset shows XANES spectra at oxygen K-edge.

We used a two step solution phase reaction to grow $\mathrm{Ni}(\mathrm{OH})_{2}$ nanocrystals on oxidized MWNTs (Supplementary Fig. S1a), which was also used for the synthesis of various other graphene hybrid nanomaterials by our group ${ }^{11,12,14-17,23}$. The resulting $\mathrm{Ni}(\mathrm{OH})_{2} /$ MWNT hybrid contained crystalline $\beta-\mathrm{Ni}(\mathrm{OH})_{2}$ nanoplates with irregular shapes interconnected by MWNTs, as revealed by scanning electron microscopy (SEM, Fig. 2a), transmission electron microscopy (TEM, Fig. 2c,d) and X-ray diffraction (Fig. 2b). The irregular shape of the $\mathrm{Ni}(\mathrm{OH})_{2}$ nanoplates was an indication of strong interaction of nanoplates with the functional groups and defects on the oxidized MWNTs ${ }^{11}$. Control experiment showed that well defined hexagonal $\mathrm{Ni}(\mathrm{OH})_{2}$ nanoplates were produced through the same reaction steps without any oxidized MWNTs added (Supplementary Fig. S2).

X-ray absorption near-edge structure (XANES) measurements were employed to probe the interactions between the $\mathrm{Ni}(\mathrm{OH})_{2}$ nanoplates and the oxidized MWNTs in the hybrid. The increased absorption intensity at $288.5 \mathrm{eV}$ (carboxyl $\pi^{\star}$ ) and $290.3 \mathrm{eV}$ (carbonate $\pi^{\star}$ ) at the carbon K-edge of the $\mathrm{Ni}(\mathrm{OH})_{2} / \mathrm{MWNT}$ hybrid (relative to oxidized MWNTs without any metal exposure through the otherwise identical reaction steps) suggested a higher concentration of oxygen functional groups on the MWNT surface bonded with $\mathrm{Ni}(\mathrm{OH})_{2}$ in the hybrid material (Fig. 2e) ${ }^{24,25}$. The nickel L-edge absorption confirmed the +2 oxidation state of $\mathrm{Ni}$ in both the $\mathrm{Ni}(\mathrm{OH})_{2} / \mathrm{MWNT}$ hybrid and the free $\mathrm{Ni}(\mathrm{OH})_{2}$ nanoplate sample (Fig. 2f). A lower nickel L-edge and a higher oxygen K-edge of the hybrid sample were observed comparing with the free $\mathrm{Ni}(\mathrm{OH})_{2}$ nanoplate sample, suggesting electron transfer from oxygen to nickel in the hybrid material (Fig. 2f) ${ }^{15,26}$. The XANES spectroscopic data confirmed strong coupling effects between $\mathrm{Ni}(\mathrm{OH})_{2}$ nanoplates and oxidized MWNTs in the hybrid.

We deposited the $\mathrm{Ni}(\mathrm{OH})_{2} / \mathrm{MWNT}$ hybrid into a Ni foam and investigated the electrochemical properties of the material in $1 \mathrm{M}$ $\mathrm{KOH}$ aqueous solution by cyclic voltammetry (CV). The electrode was measured after conditioning and activation steps (see Methods and Supplementary Fig. S3). A pair of redox peaks in the voltage range of $0-0.55 \mathrm{~V}$ vs saturated calomel electrode (SCE) was observed (Fig. 3a) and attributed to the reversible conversion between $\mathrm{Ni}(\mathrm{II})$ 

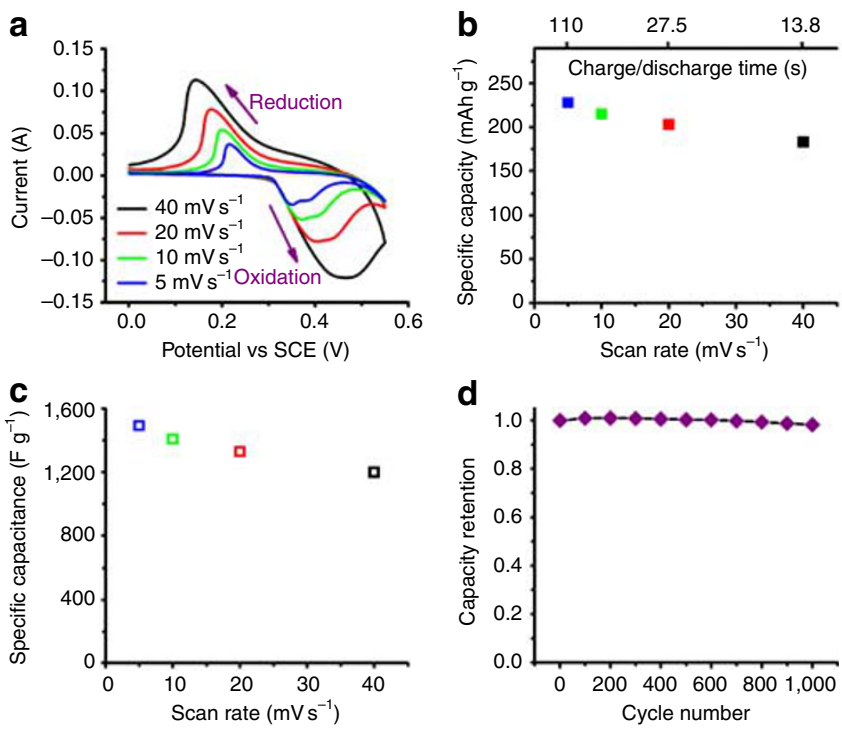

Figure 3 | $\mathrm{Ni}(\mathrm{OH})_{2} / \mathrm{MWNT}$ hybrid as a cathode material for the ultraNi-Fe battery. (a) $\mathrm{CV}$ curves of $\mathrm{Ni}(\mathrm{OH})_{2} / \mathrm{MWNT}$ hybrid at various scan rates in $1 \mathrm{M} \mathrm{KOH}$. (b) Average specific capacity of $\mathrm{Ni}(\mathrm{OH})_{2}$ nanoplates grown on oxidized MWNTs at various scan rates based on CV data in (a). (c) Average specific capacitance within a voltage range of $0.55 \mathrm{~V}$ (from $\mathrm{O} V$ to $0.55 \mathrm{~V}$ vs $\mathrm{SCE}$ ) of $\mathrm{Ni}(\mathrm{OH})_{2}$ nanoplates grown on oxidized MWNTs at various scan rates based on $\mathrm{CV}$ data in (a). (d) Cycling stability of the $\mathrm{Ni}(\mathrm{OH})_{2} / \mathrm{MWNT}$ hybrid electrode over $1,000 \mathrm{CV}$ cycles at $100 \mathrm{mV} \mathrm{s}^{-1}$. Loading of $\mathrm{Ni}(\mathrm{OH})_{2} / \mathrm{MWNT}$ was $1.1 \mathrm{mg} \mathrm{cm}^{-2}$ for the electrode.

and $\mathrm{Ni}(\mathrm{III})^{9,10,14,17}$. The $\mathrm{Ni}(\mathrm{OH})_{2}$ nanoplates on MWNTs showed a specific capacity of $228 \mathrm{mAhg}^{-1}$ and $183 \mathrm{mAhg}^{-1}$ (based on the mass of $\mathrm{Ni}(\mathrm{OH})_{2}$ ) at a scan rate of $5 \mathrm{mV} \mathrm{s}^{-1}$ and $40 \mathrm{mV} \mathrm{s}^{-1}$ (corresponding to $13.8 \mathrm{~s}$ of a full charging or discharging period, Fig. $3 \mathrm{~b}$ ) respectively, suggesting excellent rate capability of the hybrid material. The specific capacity $\left(C_{\mathrm{s}}\right)$ was calculated from the $\mathrm{CV}$ loops using $C_{\mathrm{s}}=\int i / m \mathrm{~d} t$, where $i$ was the oxidation or reduction current, $\mathrm{d} t$ was the time differential, and $m$ was the mass of the active electrode material.

With the ultrafast charging and discharging capability, the $\mathrm{Ni}(\mathrm{OH})_{2} / \mathrm{MWNT}$ hybrid could also be a pseudo-capacitor electrode material when coupled with an electric double layer (EDL) capacitor-like electrode $17,27,28$. The specific capacitance values of the $\mathrm{Ni}(\mathrm{OH})_{2}$ nanoplates on MWNTs at various $\mathrm{CV}$ scan rates (Fig. 3c) were slightly higher than the $\mathrm{Ni}(\mathrm{OH})_{2}$ nanoplates grown on graphene sheets ${ }^{14}$. The $\mathrm{Ni}(\mathrm{OH})_{2} / \mathrm{MWNT}$ hybrid electrode exhibited high cycling stability with little capacity/capacitance decay over 1,000 cycles (Fig. 3d).

$\mathrm{FeO}_{x} /$ graphene hybrid as anode for ultra-Ni-Fe battery. The anode of our ultra-Ni-Fe battery was a $\mathrm{FeO}_{x}$ /graphene hybrid, synthesized by a solution phase reaction followed by a gas phase annealing step, similar to our synthesis of a $\mathrm{Co}_{1-x} \mathrm{~S} /$ graphene hybrid reported previously $^{13}$. In the first step, $\mathrm{Fe}(\mathrm{OAc})_{2}$ was hydrolyzed in a $N, N$ dimethylformamide (DMF)/water mixed solvent at $80^{\circ} \mathrm{C}$ for coating the GO sheets selectively and uniformly with nanoparticles (Supplementary Fig. S1b). In the second step, the intermediate product from the first step was mixed with glucose and annealed in Ar at $550{ }^{\circ} \mathrm{C}$ to reduce the $\mathrm{GO}$ and make crystalline $\mathrm{FeO}_{x}$ particles on graphene.

SEM of the $\mathrm{FeO}_{x}$ /graphene hybrid (Fig. 4a) revealed dense nanoparticle coatings on the reduced GO sheets. X-ray diffraction showed that the $\mathrm{FeO}_{x}$ coating on the reduced GO was a mixture of $\mathrm{Fe}_{3} \mathrm{O}_{4}$ and metallic $\mathrm{Fe}$ (Fig. $4 \mathrm{~b}$ ). The Fe $2 p_{3 / 2}$ electron-binding energy observed in X-ray photoelectron spectroscopy (XPS) spec- trum of the $\mathrm{FeO}_{x}$ /graphene hybrid was consistent with the X-ray diffraction result, with the peaks at $705 \mathrm{eV}$ and $712 \mathrm{eV}$ corresponding to metallic iron and iron oxide, respectively (Fig. 4c). There were two types of particles grown on the graphene sheets, as observed in TEM of the $\mathrm{FeO}_{x}$ /graphene hybrid. Most of the particles were in the size range of $5-10 \mathrm{~nm}$ (Fig. $4 \mathrm{~d}, \mathrm{~g}$ ), confirmed to be $\mathrm{Fe}_{3} \mathrm{O}_{4}$ by selected area electron diffraction (Fig. 4e) and high-resolution TEM (Fig. 4g). The small sizes of the $\mathrm{Fe}_{3} \mathrm{O}_{4}$ nanoparticles were also consistent with broad $\mathrm{Fe}_{3} \mathrm{O}_{4}$ peaks in the X-ray diffraction spectrum (Fig. 4b). The other type of particles on graphene was metallic iron as evidenced by selected area electron diffraction (Fig. 4f). The size of the Fe nanoparticles was about 50-200 nm (Fig. 4a,d), giving sharp Fe peaks in the X-ray diffraction spectrum (Fig. 4b). On the basis of SEM and TEM observation, only a very small amount $(<5 \%)$ of iron oxide was reduced to metallic iron presumably by glucose during the annealing step.

The $\mathrm{FeO}_{x}$ /graphene electrode was prepared by mixing the intermediate product from the first step reaction with glucose and polytetrafluoroethylene (PTFE), depositing into $\mathrm{Ni}$ foam, and then annealing in $\mathrm{Ar}$ at $550^{\circ} \mathrm{C}$ (see Methods). It was important to load the material into $\mathrm{Ni}$ foam before high temperature annealing to afford hybrid materials uniformly dispersed and adhered to the $\mathrm{Ni}$ foam. The addition of glucose during this step was found to improve the stability of the resulting hybrid for electrochemical cycling. The electrochemical characteristics of the $\mathrm{FeO}_{x}$ /graphene electrode were investigated in $1 \mathrm{M} \mathrm{KOH}$ solutions. Multiple peaks showed up in the first several CV cycles, corresponding to various redox reactions of iron species with different oxidation states (Supplementary Fig. S4 $)^{29-31}$. After $\sim 20$ conditioning cycles, the CV curve stabilized with only one pair of redox peaks remaining (Fig. 5a), corresponding to conversion between $\mathrm{Fe}(\mathrm{II})$ and $\mathrm{Fe}(0)^{9,10,29-31}$. When scanned to the more negative potential direction, $\mathrm{Fe}(\mathrm{II})$ was reduced to $\mathrm{Fe}(0)$ before appreciable hydrogen evolution (Fig. $5 \mathrm{a}$ ). Fe(0) was oxidized to $\mathrm{Fe}(\mathrm{II})$ when scanned to the positive direction, consistent with the single oxidation peak observed in $\mathrm{CV}$ (Fig. 5a). The $\mathrm{FeO}_{x}$ nanoparticles grown on graphene exhibited a specific capacity of $377 \mathrm{mAh} \mathrm{g}^{-1}$ based on the $\mathrm{FeO}_{x}$ mass at a scan rate of $5 \mathrm{mV} \mathrm{s}^{-1}$ (Fig. 5b), corresponding to a specific pseudo-capacitance of $1,131 \mathrm{Fg}^{-1}$ within a voltage range of $1.2 \mathrm{~V}$ (Fig. $5 \mathrm{c}$ ). At a high scan rate of $40 \mathrm{mV} \mathrm{s}^{-1}$, which corresponded to a full charging or discharging time of $27.5 \mathrm{~s}$, the capacity was still as high as $317 \mathrm{mAhg}^{-1}$ (Fig. 5b). After the conditioning $\mathrm{CV}$ scans, no large Fe particles were observed in the TEM (Supplementary Fig. S5), indicating the initial Fe particles were electrochemically active and broke into small ones during the conditioning cycles. The steady redox peaks of the $\mathrm{FeO}_{x}$ /graphene hybrid were in the range of $-0.5 \mathrm{~V}$ to $-1.3 \mathrm{~V}$ vs SCE, making it a suitable electrode to pair with the $\mathrm{Ni}(\mathrm{OH})_{2} / \mathrm{MWNT}$ hybrid to form a battery.

We found that the cycling stability of the $\mathrm{FeO}_{x}$ /graphene hybrid electrode was strongly affected by parameters such as KOH concentration of the electrolyte, Fe/C ratio of the hybrid, glucose additive, and annealing temperature (Supplementary Fig. S6). In particular, glucose addition to the $\mathrm{FeO}_{x}$ /graphene hybrid material followed by thermal annealing improved cycling stability by mitigating aggregation of the $\mathrm{FeO}_{x}$ nanoparticles. SEM imaging revealed that without glucose addition, large $(\sim 200-500 \mathrm{~nm})$ rod-like structures were formed in the electrode material after $300 \mathrm{CV}$ cycles in $1 \mathrm{M} \mathrm{KOH}$ (Supplementary Figs S7a and S7b). In contrast, with glucose addition, a much lesser degree of aggregation was observed, with most of the $\mathrm{FeO}_{x}$ remaining as nanoparticles on the graphene sheets (Supplementary Figs S7c and S7d). This might be owing to a thin layer of carbon coating formed on the $\mathrm{FeO}_{x}$ nanoparticles through glucose decomposition, impeding the nanoparticles from aggregation during cycling. We used another carbon precursor, 10,10-dibromo-9, 9-bianthryl to replace glucose and obtained a $\mathrm{FeO}_{x}$ /graphene material with comparable cycling stability as the glucose-treated one. 


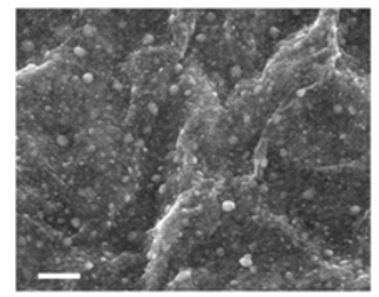

d

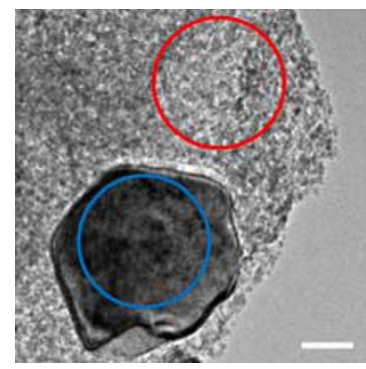

$\mathbf{g}$

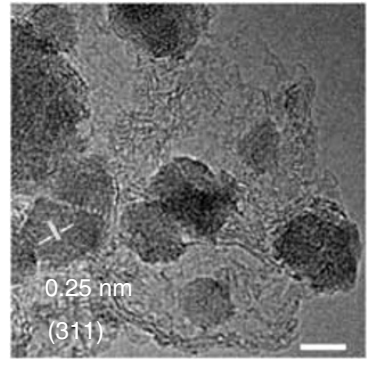

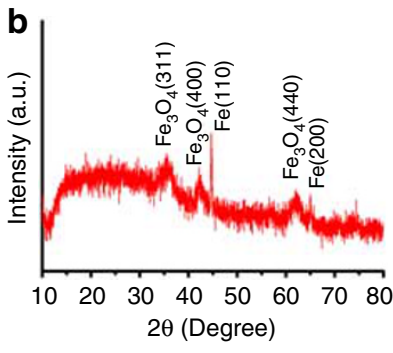
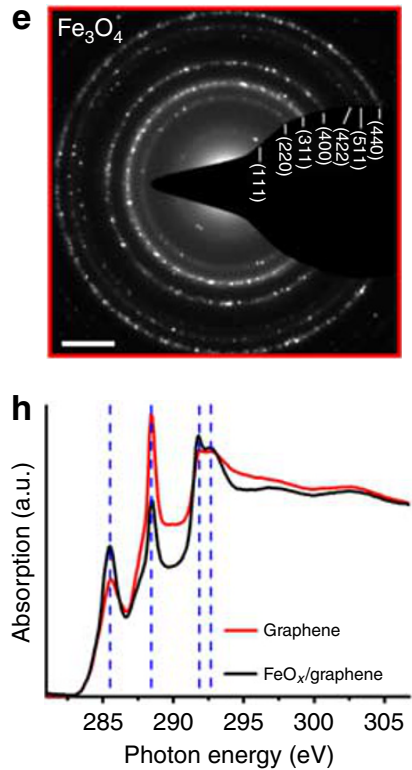
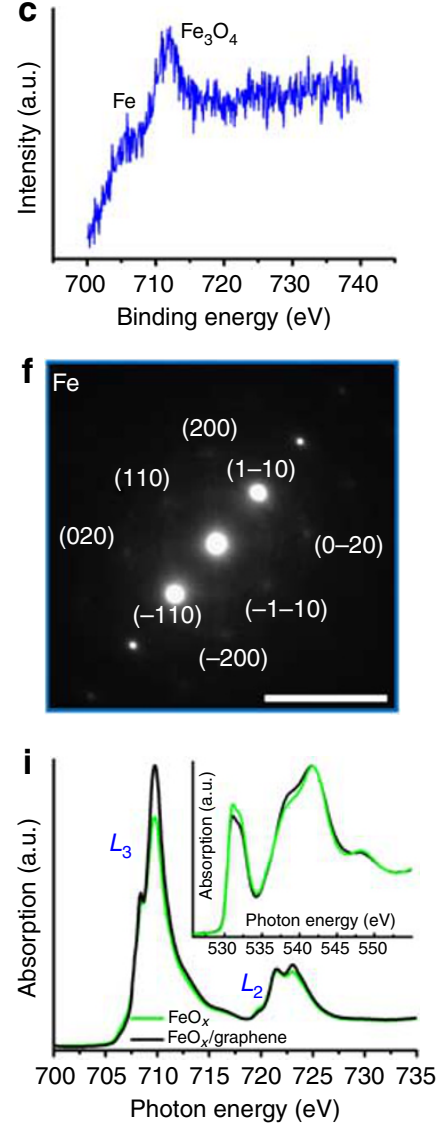

Figure 4 | $\mathbf{F e O}_{x}$ /graphene hybrid material. (a) An SEM image of the $\mathrm{FeO}_{x} /$ graphene hybrid. Scale bar, 200 nm. (b) An X-ray diffraction spectrum of a packed thick film of $\mathrm{FeO}_{x} /$ graphene. (c) An XPS spectrum of the $\mathrm{FeO}_{x} /$ graphene hybrid. (d) A TEM image of FeO $/$ /graphene showing two types of particles grown on graphene. Scale bar, $100 \mathrm{~nm}$. (e) A selected area diffraction pattern of small nanoparticles on graphene in the red circled area of (d). Scale bar, $2 \mathrm{~nm}^{-1}$. (f) A selected area diffraction pattern of a large nanoparticle on graphene in the blue circled area of (d). Scale bar, $10 \mathrm{~nm}{ }^{-1}$. (g) High-resolution TEM image of small $\mathrm{Fe}_{3} \mathrm{O}_{4}$ nanoparticles grown on graphene. Scale bar, $5 \mathrm{~nm}$. (h) XANES spectra of the $\mathrm{FeO}_{x} /$ graphene hybrid and the graphene control sample at carbon $\mathrm{K}$-edge. Blue dashed lines mark the graphene $\pi^{\star}$ absorption at $285.5 \mathrm{eV}$, carboxyl $\pi^{\star}$ absorption at $288.5 \mathrm{eV}$, and graphene $\sigma^{\star}$ absorption at 291.8 and $292.7 \mathrm{eV}$. (i) XANES spectra of the $\mathrm{FeO}_{x} /$ graphene hybrid and the $\mathrm{FeO}_{x}$ control sample at iron L-edge. The inset shows XANES spectra at oxygen K-edge.

Even with all the above parameters optimized, a discernible decay in capacity/capacitance was still observed for the $\mathrm{FeO}_{x}$ /graphene electrode over hundreds of CV cycles (Fig. 5d). This instability could be associated with the eventual aggregation of $\mathrm{FeO}_{x}$ nanoparticles through many reaction cycles, as revealed by SEM imaging of the electrode material after more than 1,000 electrochemical cycles (Supplementary Fig. S8). Aggregation of the $\mathrm{FeO}_{x}$ nanoparticles indicated the loss of nanoparticle bonding and coupling with the conducting graphene sheets, leading to reduced electrochemical activity.

To understand the excellent electrochemical capacity and rate performance of the $\mathrm{FeO}_{x}$ /graphene hybrid, we performed XANES measurements to investigate the interactions between $\mathrm{FeO}_{x}$ nanoparticles and graphene in the hybrid. To avoid interference with the carbon signal from graphene, no glucose was added in the annealing step of the sample prepared for XANES. At the carbon K-edge (Fig.4h), the $\mathrm{FeO}_{x}$ /graphene hybrid showed a clear increase in absorption intensity at $285.5 \mathrm{eV}$ compared with a control-reduced GO sample that had gone through the same synthesis and processing steps as the hybrid except for without adding any $\mathrm{Fe}(\mathrm{OAc})_{2}$. This increased absorption suggested a higher $\pi^{\star}$ density and thus enhanced $s p^{2}$ bonding characteristics ${ }^{24}$. This was consistent with the better resolved resonances, at 291.8 and $292.7 \mathrm{eV}$, that indicated a more restored graphitic lattice in the hybrid ${ }^{24}$. The absorption peak at $288.5 \mathrm{eV}$ (carboxyl $\pi^{\star}$ ) near the carbon K-edge was attributed to $\mathrm{C}-\mathrm{O}$ functional groups in the reduced $\mathrm{GO}$ and could be affected by covalent $\mathrm{Fe}-\mathrm{O}-\mathrm{C}$ bonding 24,25 . At the iron L-edge XANES (Fig. 4i), the $\mathrm{L}_{3}$ and $\mathrm{L}_{2}$ peaks were consistent with the $\mathrm{Fe}_{3} \mathrm{O}_{4}$ phase ${ }^{32,33}$. The increased iron L-edge and the decreased oxygen K-edge (Fig. 4i inset) of the hybrid compared with the free $\mathrm{FeO}_{x}$ control suggested an increase in the unoccupied electron density states at the $\mathrm{O}$ site and a decrease in the unoccupied electron density states at the $\mathrm{Fe}$ site, consequently a higher ionic $\mathrm{Fe}-\mathrm{O}$ bonding in the hybrid ${ }^{15,26}$.

Ultra-Ni-Fe battery made of $\mathrm{Ni}(\mathrm{OH})_{2} / \mathrm{MWNT}$ and $\mathrm{FeO}_{x}$ / graphene. A two-electrode ultra-Ni-Fe cell was fabricated by using the $\mathrm{Ni}(\mathrm{OH})_{2} / \mathrm{MWNT}$ hybrid material as the cathode and the $\mathrm{FeO}_{x} /$ graphene hybrid material as the anode in $1 \mathrm{M} \mathrm{KOH}$ (Fig. 6a, $1.1 \mathrm{mg}$ of $\mathrm{Ni}(\mathrm{OH})_{2} / \mathrm{MWNT}$ and $0.7 \mathrm{mg}$ of $\mathrm{FeO}_{x} /$ graphene were loaded into $1 \mathrm{~cm}^{2} \mathrm{Ni}$ foams to form the electrodes). The mass ratio of $\mathrm{Ni}(\mathrm{OH})_{2} /$ $\mathrm{FeO}_{x}$ was chosen to balance the cathode capacity with the anode capacity. CV curves of the ultra-Ni-Fe cell at various scan rates corresponding to a full charging or discharging time from $\sim 20 \mathrm{~s}$ to $\sim 3$ min are shown in Fig. 6a. At such high charging and discharging rates, the ultra-Ni-Fe cell was able to achieve high specific capacity 

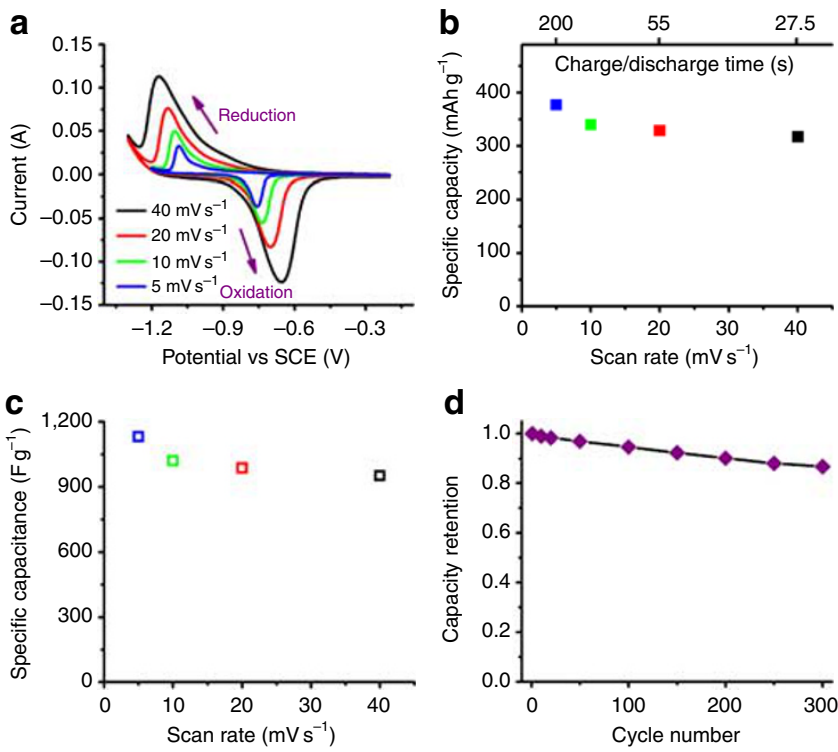

Figure 5 | $\mathrm{FeO}_{x} /$ graphene hybrid as an anode material for the ultra-Ni-Fe battery. (a) $\mathrm{CV}$ curves of $\mathrm{FeO}_{x}$ /graphene hybrid at various scan rates in $1 \mathrm{M} \mathrm{KOH}$. (b) Average specific capacity of $\mathrm{FeO}_{x}$ nanoparticles grown on graphene at various scan rates based on CV data in (a). (c) Average specific capacitance within a voltage range of $1.2 \mathrm{~V}$ (from $-0.2 \mathrm{~V}$ to $-1.4 \mathrm{~V}$ vs $\mathrm{SCE}$ ) of $\mathrm{FeO}_{x}$ nanoparticles grown on graphene at various scan rates based on CV data in (a). (d) Cycling stability of the $\mathrm{FeO}_{x} /$ graphene hybrid over $300 \mathrm{CV}$ cycles at $40 \mathrm{mV} \mathrm{s}^{-1}$. Loading of $\mathrm{FeO}_{x} /$ graphene was $\sim 0.7 \mathrm{mg} \mathrm{cm}^{-2}$ for the electrode.

from $102 \mathrm{mAhg}^{-1}$ to $125 \mathrm{mAhg}^{-1}$ based on total mass of the active materials (Fig. 6b), confirming the exceptional rate capability of the hybrid nanomaterials.

The ultra-Ni-Fe cell performance was further evaluated by galvanostatic measurements. Figure $6 \mathrm{c}$ shows discharging voltage profiles of the ultra-Ni-Fe cell at various current densities. Charging was performed at a current density of $3.7 \mathrm{Ag}^{-1}$. To calculate the specific capacity, we used the equation $C_{\mathrm{s}}=I \Delta t / \mathrm{m}$, where $I$ was the discharging current, $\Delta t$ was discharging time, and $m$ was the total mass of the active electrode materials. At high discharging current densities from $1.5 \mathrm{Ag}^{-1}$ to $37 \mathrm{Ag}^{-1}$, our ultra-Ni-Fe cell was able to deliver specific capacity ranging from $126 \mathrm{mAh}^{-1}$ to $104 \mathrm{mAh}^{-1}$ (Fig. 6c), based on the total mass of the active materials. This was consistent with the capacity values measured by CV (Fig. 6b). Discharge at various rates as shown in Fig. 6c was completed in from $\sim 5 \mathrm{~min}$ to $\sim 9 \mathrm{~s}$, and charging was completed in about $2 \mathrm{~min}$, much faster than conventional $\mathrm{Ni}-\mathrm{Fe}$ batteries that need to be charged and discharged in hours ${ }^{9,10}$. Our battery also outperformed a recently reported $\mathrm{Ni}-\mathrm{Fe}$ battery (made from $\mathrm{Fe}_{2} \mathrm{O}_{3}$ nanorods supported on carbon nanofibres and $\beta-\mathrm{Ni}(\mathrm{OH})_{2}$ ) with a specific capacity of $\sim 80 \mathrm{mAh} \mathrm{g}^{-1}$ (based on active material mass) and hour-scale charging and discharging times ${ }^{34}$. Thus, the ultra-Fe-Ni battery made of strongly coupled hybrid materials afforded unprecedented high-rate performance of rechargeable batteries in an aqueous electrolyte. The average discharge voltages of our ultra-Ni-Fe cell shown in Fig. $6 \mathrm{c}$ were from $\sim 1.1 \mathrm{~V}$ to $\sim 0.95 \mathrm{~V}$, making it a feasible cell for energy storage.

\section{Discussion}

The energy and power densities $\left(d_{e}\right.$ and $\left.d_{p}\right)$ were calculated for the ultra-Ni-Fe cell and shown in the Ragone plot in Fig. 6d, using equations $\mathrm{d}_{e}=\int I V \mathrm{~d} t / m$ and $d_{p}=d_{e} / \Delta t$, where $I$ was the discharging current, $V$ was discharging voltage, $\mathrm{d} t$ was time differential,
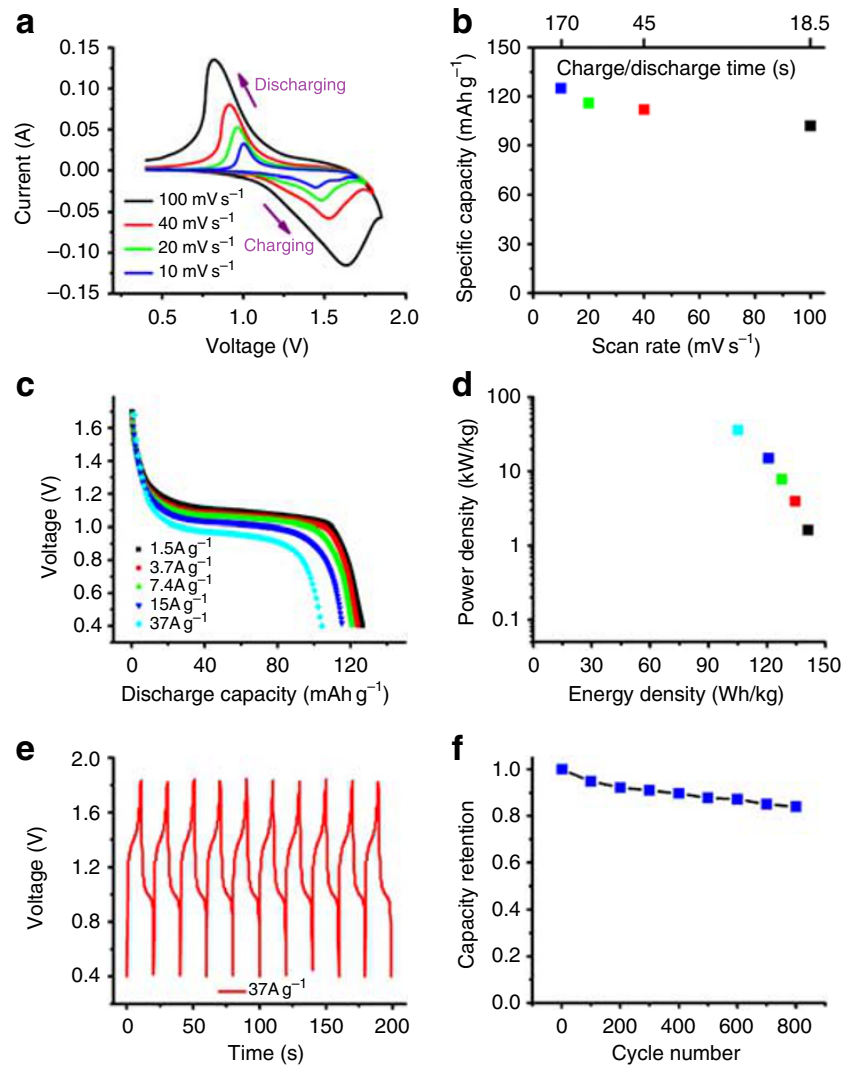

Figure 6 | Ultra-Ni-Fe battery made of $\mathrm{Ni}(\mathrm{OH})_{2} / \mathrm{MWNT}$ and

$\mathbf{F e O}_{\boldsymbol{x}}$ /graphene. (a) $\mathrm{CV}$ curves at various scan rates in two-electrode configuration in $1 \mathrm{M} \mathrm{KOH}$. $1.1 \mathrm{mg}$ of $\mathrm{Ni}(\mathrm{OH})_{2} / \mathrm{MWNT}$ and $0.7 \mathrm{mg}$ of $\mathrm{FeO}_{x} /$ graphene were loaded into $1 \mathrm{~cm}^{2} \mathrm{Ni}$ foams to form the electrodes. (b) Two-electrode specific capacity of the ultra-Ni-Fe battery at various scan rates based on CV data in (a). (c) Galvanostatic discharge curves at various current densities. Charging was performed at $3.7 \mathrm{Ag}^{-1}$ till $1.67 \mathrm{~V}$. (d) Ragone plot of the ultra-Ni-Fe battery measured in (c). (e) Galvanostatic charge and discharge curves of the ultra-Ni-Fe at a current density of $37 \mathrm{Ag}^{-1}$. (f) Capacity retention vs cycle number for the ultra-Ni-Fe battery at a galvanostatic charge and discharge current density of $37 \mathrm{Ag}^{-1}$.

$m$ was the total mass of the active electrode materials, and $\Delta t$ was the discharging time. Our ultra-Ni-Fe cell showed an energy density of $141 \mathrm{Wh} \mathrm{kg}^{-1}$ at a power density of $1.6 \mathrm{~kW} \mathrm{~kg}^{-1}$, and a power density of $36 \mathrm{~kW} \mathrm{~kg}^{-1}$ at an energy density of $105 \mathrm{Wh} \mathrm{kg}^{-1}$. This suggested nearly 1,000 -fold increase of the power rate of $\mathrm{Ni}-\mathrm{Fe}$ batteries without losing energy capacity.

Cycle life of the ultra-Ni-Fe cell was measured by galvanostatic measurements at a current density of $37 \mathrm{Ag}^{-1}$ (Fig. 6e). Coulombic efficiency was near $100 \%$ during the ultrafast cycling (Fig. 6e). About $\sim 80 \%$ of the initial capacity was maintained after 800 cycles of charge-discharge (Fig. 6f). The capacity decay was most likely due to the $\mathrm{FeO}_{x} /$ graphene electrode rather than the $\mathrm{Ni}(\mathrm{OH})_{2} / \mathrm{MWNT}$ electrode, which could be deduced from the half-cell performances of the two electrodes (Figs $5 \mathrm{~d}$ and $3 \mathrm{~d}$ ) $^{34}$. Even faster capacity decay was observed in a recent $\mathrm{Ni}$-Fe battery made from $\mathrm{Fe}_{2} \mathrm{O}_{3}$ nanorods supported on carbon nanofibres and $\beta-\mathrm{Ni}(\mathrm{OH})_{2}(\sim 8 \%$ decay for 100 cycles $)^{34}$. Further work is needed to further understand and eliminate the decay of the $\mathrm{FeO}_{x}$ /graphene anode. Nevertheless, because of the low cost, high safety and environmentally friendliness, the ultra-Ni-Fe battery with ultrafast charge and discharge at high energy density holds promise for power quality applications ranging 
from portable electronics, emergency power supply, transportation, and electrical grid.

With increased mass loading of electrode materials (1.9$3.0 \mathrm{mg} \mathrm{cm}^{-2}$ for $\mathrm{Ni}(\mathrm{OH})_{2} / \mathrm{MWNT}$ and $1.4-2.1 \mathrm{mg} \mathrm{cm}^{-2}$ for $\mathrm{FeO}_{x} /$ graphene), specific capacity in the range of $\sim 105-125 \mathrm{mAhg}^{-1}$ was obtained for the ultra-Ni-Fe battery (Supplementary Fig. S9), compared with $\sim 125 \mathrm{mAhg}^{-1}$ at $1.1 \mathrm{mg} \mathrm{cm}^{-2}$ of $\mathrm{Ni}(\mathrm{OH})_{2} /$ MWNT and $0.7 \mathrm{mg} \mathrm{cm}^{-2}$ of $\mathrm{FeO}_{x} /$ graphene (Fig. 6). We compared our ultra-Ni-Fe cell with an EDL supercapacitor made up of high performance activated carbon $\left(\sim 300 \mathrm{Fg}^{-1}\right.$ at $\left.\sim 1 \mathrm{mg} \mathrm{cm}^{-2}\right)$ in the same $\mathrm{KOH}$ aqueous electrolyte (Supplementary Fig. S10). With $\sim 5$-fold lower active material mass, the ultra-Ni-Fe cell provided $\sim 2$-fold higher energy and power than the EDL supercapacitor with mass loading of $\sim 10 \mathrm{mg} \mathrm{cm}^{-2}$ (Supplementary Figs S11a and S11c), suggesting the ultra-Ni-Fe battery with more than an order of magnitude higher specific energy and power (Supplementary Figs S11b and S11d) than typical supercapacitors in aqueous electrolytes.

The superior performance of the ultra-Ni-Fe cell is attributed to the unique structures of the inorganic/carbon hybrid materials. The $\mathrm{Ni}(\mathrm{OH})_{2}$ nanoplates and $\mathrm{FeO}_{x}$ nanoparticles are directly and selectively grown on the nanocarbon substrates. The bonding and coupling between the nano-sized active materials and nanocarbon in the hybrid structures drastically enhance charge transfer in the electrodes. In a control experiment, we synthesized free $\mathrm{Ni}(\mathrm{OH})_{2}$ nanoplates and $\mathrm{FeO}_{x}$ nanoparticles following the same procedures as for the hybrid materials but without any nanocarbon added. Their mixtures with carbon black showed much lower specific capacities than the hybrid materials (Supplementary Fig. S12). This clearly demonstrates the advantage of our inorganic/carbon hybrid materials.

In summary, we have synthesized new $\mathrm{Ni}(\mathrm{OH})_{2} / \mathrm{MWNT}$ and $\mathrm{FeO}_{x} /$ graphene hybrid materials with excellent electrochemical performances by utilizing the high conductivity of the graphitic carbon materials and strong coupling between inorganic nanocrystals and oxidized nanocarbon. Pairing of the two hybrid materials affords an ultrafast version of Ni-Fe battery capable of charge and discharge in seconds. With comparable energy density as conventional $\mathrm{Ni}-\mathrm{Fe}$ batteries, the new ultra-Ni-Fe battery achieves nearly 1,000 times higher power density, making it a high-performance, low cost, safe and environmentally benign energy storage device.

\footnotetext{
Methods

Making of GO and oxidized MWNTs. GO was made by a modified Hummers method. Graphite flakes (1 g, Superior Graphite) were ground with $\mathrm{NaCl}(\sim 10 \mathrm{~g})$ for $10 \mathrm{~min}$. Afterwards, $\mathrm{NaCl}$ was washed away by repeatedly rinsing with water in a vacuum filtration apparatus. The remaining graphite was heated at $70^{\circ} \mathrm{C}$ in an oven for $20 \mathrm{~min}$ to remove the remaining water. The dried solid was then combined with $23 \mathrm{ml}$ of concentrated sulphuric acid in a $250 \mathrm{ml}$ round bottom flask and stirred at room temperature for $24 \mathrm{~h}$. Next, the flask was placed in an oil bath at $40^{\circ} \mathrm{C}$ and $100 \mathrm{mg}$ of $\mathrm{NaNO}_{3}$ was added to the suspension and allowed to be dissolved for $5 \mathrm{~min}$. This step was followed by the slow addition of $500 \mathrm{mg}$ ( $3 \mathrm{~g}$ for the Hummers GO) of $\mathrm{KMnO}_{4}$, keeping the temperature below $45^{\circ} \mathrm{C}$. The solution was allowed to stir for $30 \mathrm{~min}$. Afterwards, $3 \mathrm{ml}$ of water was added to the flask, followed by another $3 \mathrm{ml}$ after $5 \mathrm{~min}$. In another $5 \mathrm{~min}, 40 \mathrm{ml}$ of water was added. After $15 \mathrm{~min}$, the solution was removed from the oil bath and $140 \mathrm{ml}$ of water and $10 \mathrm{ml}$ of $30 \% \mathrm{H}_{2} \mathrm{O}_{2}$ were added to end the reaction. This suspension was stirred at room temperature for $5 \mathrm{~min}$. The suspension was then repeatedly centrifuged and washed twice with $5 \% \mathrm{HCl}$ solution and then repeatedly with water. The collected precipitate was dispersed in $150 \mathrm{ml}$ of anhydrous DMF and cup-horn sonicated for $20 \mathrm{~min}$. After 5,000 r.p.m. centrifuge $(3,020 \mathrm{~g})$ for $5 \mathrm{~min}$, a dark brown homogeneous supernatant was obtained. Oxidized MWNTs were made by a modified Hummers method. MWNTs (1 g, FloTube 9000 from CNano Technology) were first purified by calcination at $500^{\circ} \mathrm{C}$ for $1 \mathrm{~h}$ and washing with diluted hydrochloric acid (10\%). The purified MWNTs were put into a $250 \mathrm{ml}$ round-bottom flask. $23 \mathrm{ml}$ of concentrated sulphuric acid was added and the mixture was stirred at room temperature overnight. Next, the flask was heated in an oil bath at $40^{\circ} \mathrm{C}$ and $350 \mathrm{mg}$ of $\mathrm{NaNO}_{3}$ was added to the suspension and allowed to be dissolved for $5 \mathrm{~min}$. This step was followed by the slow addition of $2 \mathrm{~g}$ of $\mathrm{KMnO}_{4}$, keeping the reaction temperature below $45^{\circ} \mathrm{C}$. The solution was stirred for $30 \mathrm{~min}$.
}

Afterwards $3 \mathrm{ml}$ of water was added to the flask, followed by another $3 \mathrm{ml}$ after $5 \mathrm{~min}$. After another $5 \mathrm{~min}, 40 \mathrm{ml}$ of water was added. $15 \mathrm{~min}$ later, the flask was removed from the oil bath and $140 \mathrm{ml}$ of water and $10 \mathrm{ml}$ of $30 \% \mathrm{H}_{2} \mathrm{O}_{2}$ were added to end the reaction. This suspension was stirred at room temperature for $5 \mathrm{~min}$. It was then repeatedly centrifuged and washed with $5 \% \mathrm{HCl}$ solution twice, followed by rinsing with copious amounts of water. The final precipitate was dispersed in $10 \mathrm{ml}$ of water and lyophilized. Finally, a dry product of $\sim 1 \mathrm{~g}$ was collected.

Synthesis of $\mathrm{Ni}(\mathrm{OH})_{2} / \mathbf{M W N T}$ hybrid and $\mathrm{FeO}_{x} /$ graphene hybrid. In a typical synthesis of $\mathrm{Ni}(\mathrm{OH})_{2} / \mathrm{MWNT}$ hybrid, $\sim 4 \mathrm{mg}$ of oxidized MWNTs were dispersed in $8 \mathrm{ml}$ of anhydrous DMF, to which $0.8 \mathrm{ml}$ of $0.2 \mathrm{M} \mathrm{Ni}(\mathrm{OAc})_{2}$ aqueous solution was added. The suspension was kept at $80^{\circ} \mathrm{C}$ with magnetic stirring for $4 \mathrm{~h}$. After that, the intermediate product was collected by centrifuge and washing with water. The intermediate product was then dispersed in $\sim 12 \mathrm{ml}$ of water. The suspension was then sealed in a $40-\mathrm{ml}$ Teflon-lined stainless steel autoclave for hydrothermal reaction at $180^{\circ} \mathrm{C}$ for $12 \mathrm{~h}$. The final product was collected by centrifuge, water-washing and lyophilization. To synthesize the $\mathrm{FeO}_{x} /$ graphene hybrid, $0.8 \mathrm{ml}$ of $0.2 \mathrm{M} \mathrm{Fe}(\mathrm{OAc})_{2}$ aqueous solution was added to $8 \mathrm{ml}$ of GO DMF suspension $\left(\sim 0.3 \mathrm{mg} \mathrm{ml}^{-1}\right)$. The suspension was kept at $80^{\circ} \mathrm{C}$ with magnetic stirring for $2 \mathrm{~h}$. After that, the intermediate product was collected by centrifugation, washed with water, and lyophilized. The intermediate product was then mixed with glucose and annealed in $\mathrm{Ar}$ at $550^{\circ} \mathrm{C}$ for $1 \mathrm{~h}$ to produce the final $\mathrm{FeO}_{x} /$ graphene hybrid (To prepare the $\mathrm{FeO}_{x} /$ graphene electrode with optimal dispersion of the hybrid material, the material was first loaded into Ni foam and then annealed; see below). There was a mass loss of $\sim 40 \%$ associated with this step, owing to evaporation of adsorbed and hydrated water in the material. The mass ratios of nanocarbon in the hybrid materials were determined by thermal gravimetric experiments, in which the hybrid materials were heated in air at $500^{\circ} \mathrm{C}$ for $3 \mathrm{~h}$. The MWNTs and graphene were burned away and $\mathrm{Ni}(\mathrm{OH})_{2}$ and $\mathrm{FeO}_{x}$ were transformed to $\mathrm{NiO}$ and $\mathrm{Fe}_{2} \mathrm{O}_{3}$, respectively. The mass ratios of nanocarbon were then calculated accordingly, based on the mass loss of the materials. We found that the $\mathrm{Ni}(\mathrm{OH})_{2} / \mathrm{MWNT}$ hybrid contained $\sim 30 \%$ of MWNTs by mass and the $\mathrm{FeO}_{x} /$ graphene hybrid contained $\sim 20 \%$ of graphene by mass.

Characterization. SEM was carried out on an FEI XL30 Sirion scanning electron microscope. TEM was carried out on an FEI Tecnai G2 F20 transmission electron microscope. X-ray diffraction was carried out on a PANalytical X'Pert instrument. XPS measurement was performed on an SSI S-Probe XPS Spectrometer. XANES data were recorded in the surface-sensitive total electron yield with the use of specimen current. Data were first normalized to the incident photon flux $I_{0}$ measured with a refreshed gold mesh at SGM before the measurement. After background correction, the XANES are then normalized to the edge jump, the difference in absorption coefficient just below and at a flat region above the edge. $\mathrm{CV}$ and chronopotentiometry were carried out on a $\mathrm{CHI} 760 \mathrm{D}$ electrochemistry workstation.

Preparation of working electrodes. To prepare the $\mathrm{Ni}(\mathrm{OH})_{2} / \mathrm{MWNT}$ electrode, $\mathrm{Ni}(\mathrm{OH})_{2} / \mathrm{MWNT}$ hybrid material was first mixed with PTFE (from 60wt.\%. water suspension, Aldrich) in a ratio of 100:2 by weight, and then dispersed in ethanol; the suspension was drop-dried into a $1 \mathrm{~cm} \times 1 \mathrm{~cm} \mathrm{Ni}$ foam (2-mm thick, $100 \mathrm{ppi}$ $95 \%$ porosity, Marketech) at $80^{\circ} \mathrm{C}$; the electrode was then baked at $120^{\circ} \mathrm{C}$ for $20 \mathrm{~min}$; the electrode was compressed to $\sim 0.5 \mathrm{~mm}$ thick before measurement. To prepare the $\mathrm{FeO}_{x}$ /graphene hybrid electrode, the intermediate product after the first-step reaction at $80^{\circ} \mathrm{C}$ was first mixed with glucose and PTFE in a ratio of 100:20:5 by weight, and then dispersed in ethanol; the suspension was drop-dried into a $1 \mathrm{~cm} \times 1 \mathrm{~cm} \mathrm{Ni}$ foam at $80^{\circ} \mathrm{C}$. The electrode was then annealed in 1 Torr Ar at $550^{\circ} \mathrm{C}$ for $1 \mathrm{~h}$; the annealed electrode was compressed to $\sim 0.5 \mathrm{~mm}$ thickness before measurement. All the working electrodes in this work were prepared following the above procedures unless otherwise noted. Electrodes of free $\mathrm{Ni}(\mathrm{OH})_{2}$ and $\mathrm{FeO}_{x}$ mixed with carbon black were prepared in the same way as the hybrid electrodes except that mixtures were used to replace the hybrid materials. To prepare the activated carbon electrode, activated carbon was mixed with carbon black and polyvinylidene difluoride in a ratio of 10:1:1 in $\mathrm{N}$-methyl-2-pyrrolidone by magnetic stirring for $12 \mathrm{~h}$. The mixture was then pasted onto Ni foam, dried at $80^{\circ} \mathrm{C}$ and further baked at $200^{\circ} \mathrm{C}$ for $1 \mathrm{~h}$ in air. Mass loadings for the pasted electrodes were determined by comparing the mass of the electrode with that of the original blank Ni foam.

Electrochemical measurements. Electrochemical measurements were carried out in a beaker cell with $1 \mathrm{M} \mathrm{KOH}$ aqueous solution as the electrolyte. CV measurements of the $\mathrm{Ni}(\mathrm{OH})_{2} / \mathrm{MWNT}$ and $\mathrm{FeO}_{x} /$ graphene electrodes were performed in a three-electrode configuration, where a SCE was used as the reference electrode, and a graphite rod was used as the counter electrode. Conditioning and activation steps were applied to the $\mathrm{Ni}(\mathrm{OH})_{2} / \mathrm{MWNT}$ electrode before electrochemical data were taken. 200 conditioning CV scans at $40 \mathrm{mV} \mathrm{s}^{-1}$ were first performed, and then the electrode was dried without rinsing off the electrolyte solution and kept in ambient conditions for 3-10 days for activation. We found electrodes with higher mass loadings of the $\mathrm{Ni}(\mathrm{OH})_{2} / \mathrm{MWNT}$ material took longer to be activated. Blank Ni foam that went through the same conditioning and activation steps as the 
$\mathrm{Ni}(\mathrm{OH})_{2} / \mathrm{MWNT}$ hybrid electrode showed negligible capacity compared with the hybrid electrode (Supplementary Fig. S3). The activation step was not effective for the blank Ni foam (Supplementary Fig. S3). The Ni-Fe battery was measured in a two-electrode configuration, where the reference lead was connected to the counter electrode lead. The $\mathrm{Ni}(\mathrm{OH})_{2} / \mathrm{MWNT}$ electrode was pre-scanned against the reference electrode at $40 \mathrm{mV} \mathrm{s}^{-1}$ for 200 cycles and left dried with $\mathrm{KOH}$ solution inside for 3-10 days to stabilize the capacitance/capacity before further measurements. The $\mathrm{FeO}_{x} /$ graphene electrode was pre-scanned against the reference electrode at $100 \mathrm{mV} \mathrm{s}^{-1}$ for 20 cycles to stabilize the capacitance/capacity before further measurements. For all the electrodes, we performed experiments to make sure that the capacitance contribution from the $\mathrm{Ni}$ foam was negligible.

\section{References}

1. Armand, M. \& Tarascon, J. M. Building better batteries. Nature 451, 652-657 (2008).

2. Goodenough, J. B. \& Kim, Y. Challenges for rechargeable batteries. J. Power Sources 196, 6688-6694 (2011)

3. Scrosati, B., Hassoun, J. \& Sun, Y.- K. Lithium-ion batteries. A look into the future. Energy Environ. Sci. 4, 3287-3295 (2011).

4. Cheng, F., Liang, J., Tao, Z. \& Chen, J. Functional materials for rechargeable batteries. Adv. Mater. 23, 1695-1715 (2011).

5. Park, O. K. et al. Who will drive electric vehicles, olivine or spinel? Energy Environ. Sci. 4, 1621-1633 (2011).

6. Etacheri, V., Marom, R., Elazari, R., Salitra, G. \& Aurbach, D. Challenges in the development of advanced Li-ion batteries: a review. Energy Environ. Sci. 4, 3243-3262 (2011)

7. Goodenough, J. B. \& Kim, Y. Challenges for rechargeable Li batteries. Chem Mater. 22, 587-603 (2010).

8. Bruce, P. G., Scrosati, B. \& Tarascon, J.- M. Nanomaterials for rechargeable lithium batteries. Angew. Chem. Int. Ed. 47, 2930-2946 (2008).

9. Halpert, G. Past developments and the future of nickel electrode cell technology. J. Power Sources 12, 177-192 (1984).

10. Chakkaravarthy, C., Periasamy, P., Jegannathan, S. \& Vasu, K. I. the nickel iron battery. J. Power Sources 35, 21-35 (1991).

11. Wang, H. L., Robinson, J. T., Diankov, G. \& Dai, H. J. Nanocrystal growth on graphene with various degrees of oxidation. J. Am. Chem. Soc. 132, 3270-3271 (2010)

12. Wang, H. L. et al. $\mathrm{LiMn}_{1-x} \mathrm{Fe}_{x} \mathrm{PO}_{4}$ nanorods grown on graphene sheets for ultrahigh-rate-performance lithium ion batteries. Angew. Chem. Int. Ed. 50, 7364-7368 (2011)

13. Wang, H., Liang, Y., Li, Y. \& Dai, H. $\mathrm{Co}_{1-x} \mathrm{~S}$-graphene hybrid: a highperformance metal chalcogenide electrocatalyst for oxygen reduction. Angew. Chem. Int. Ed. 50, 10969-10972 (2011).

14. Wang, H. L., Casalongue, H. S., Liang, Y. Y. \& Dai, H. J. Ni(OH $)_{2}$ nanoplates grown on graphene as advanced electrochemical pseudocapacitor materials. J. Am. Chem. Soc. 132, 7472-7477 (2010).

15. Liang, Y. Y. et al. $\mathrm{Co}_{3} \mathrm{O}_{4}$ nanocrystals on graphene as a synergistic catalyst for oxygen reduction reaction. Nat. Mater. 10, 780-786 (2011).

16. Liang, Y. et al. Covalent hybrid of spinel manganese-cobalt oxide and graphene as advanced oxygen reduction electrocatalysts. J. Am. Chem. Soc. 134, 3517-3523 (2012)

17. Wang, H. L. et al. Advanced asymmetrical supercapacitors based on graphene hybrid materials. Nano Res. 4, 729-736 (2011).

18. Li, Y. G. et al. An oxygen reduction electrocatalyst based on carbon nanotubegraphene complexes. Nature Nanotechnol. doi:10.1038/nnano.2012.72.

19. Wei, F. et al. The mass production of carbon nanotubes using a nanoagglomerate fluidized bed reactor: A multiscale space-time analysis. Powder Technol. 183, 10-20 (2008).

20. Zhang, Q., Huang, J.- Q., Zhao, M.- Q., Qian, W.- Z. \& Wei, F. Carbon nanotube mass production: principles and processes. Chemsuschem 4, 864-889 (2011).

21. Wang, Y., Wei, F., Luo, G. H., Yu, H. \& Gu, G. S. The large-scale production of carbon nanotubes in a nano-agglomerate fluidized-bed reactor. Chem. Phys. Lett. 364, 568-572 (2002).
22. Qian, W. Z. et al. Production of carbon nanotubes in a packed bed and a fluidized bed. Aiche J. 49, 619-625 (2003).

23. Wang, H. L. et al. $\mathrm{Mn}_{3} \mathrm{O}_{4}$-graphene hybrid as a high-capacity anode material for lithium ion batteries. J. Am. Chem. Soc. 132, 13978-13980 (2010).

24. Zhan, D. et al. Electronic structure of graphite oxide and thermally reduced graphite oxide. Carbon 49, 1362-1366 (2011).

25. Zhou, J. G. et al. Immobilization of $\mathrm{RuO}_{2}$ on carbon nanotube: an $\mathrm{x}$-ray absorption near-edge structure study. J. Phys. Chem. C 113, 10747-10750 (2009)

26. Zhou, J. G. et al. Electronic structure of $\mathrm{TiO}_{2}$ nanotube arrays from X-ray absorption near edge structure studies. J. Mater. Chem. 19, 6804-6809 (2009).

27. Gao, Z. et al. Graphene nanosheet/ $/ \mathrm{Ni}^{2+} / \mathrm{Al}^{3+}$ layered double-hydroxide composite as a novel electrode for a supercapacitor. Chem. Mater. 23, 3509-3516 (2011).

28. Lee, J. W., Ahn, T., Soundararajan, D., Ko, J. M. \& Kim, J. D. Non-aqueous approach to the preparation of reduced graphene oxide/alpha- $\mathrm{Ni}(\mathrm{OH})_{2}$ hybrid composites and their high capacitance behavior. Chem. Commun. 47, 6305-6307 (2011).

29. Periasamy, P., Babu, B. R. \& Iyer, S. V. Cyclic voltammetric studies of porous iron electrodes in alkaline solutions used for alkaline batteries. J. Power Sources 58, 35-40 (1996)

30. Vijayamohanan, K., Balasubramanian, T. S. \& Shukla, A. K. Rechargeable alkaline iron electrodes. J. Power Sources 34, 269-285 (1991).

31. Kao, C.- Y., Tsai, Y.- R. \& Chou, K.- S. Synthesis and characterization of the iron/copper composite as an electrode material for the rechargeable alkaline battery. J. Power Sources 196, 5746-5750 (2011).

32. Thakur, P. et al. X-ray absorption spectroscopic studies of pulsed-laserdeposited thin films of $\mathrm{Fe}_{3} \mathrm{O}_{4}$ on $\mathrm{Si}(111)$ substrate. J. Korean Phys. Soc. 53, 3694-3698 (2008).

33. Kuiper, P., Searle, B. G., Rudolf, P., Tjeng, L. H. \& Chen, C. T. X-ray magnetic dichroism of antiferromagnet $\mathrm{Fe}_{2} \mathrm{O}_{3}$ : the orientation of magnetic moments observed by Fe 2 p x-ray absorption spectroscopy. Phys. Rev. Lett. 70, $1549-1552$ (1993).

34. Liu, Z., Tay, S. W. \& Li, X. Rechargeable battery using a novel iron oxide nanorods anode and a nickel hydroxide cathode in an aqueous electrolyte. Chem. Commun. 47, 12473-12475 (2011).

\section{Acknowledgements}

This work is supported by Intel, a Stinehart/Reed Award for Energy Research at Stanford from the Stanford Precourt Institute for Energy, and a Stanford Graduate Fellowship. CLS is supported by the NSERC, NRC, CIHR of Canada, and the University of Saskatchewan.

\section{Author contributions}

H.W. and H.D. conceived the project and designed the experiments. H.W., Y.Liang, M.G., Y.Li, W.C., T.M., J.Z., J.W. and T.R. performed the experiments and analysed the data. F.W. provided the MWNT material. H.W. and H.D. co-wrote the paper.

\section{Additional information}

Supplementary Information accompanies this paper at http://www.nature.com/ naturecommunications

Competing financial interests: The authors declare no competing financial interests.

Reprints and permission information is available online at http://npg.nature.com/ reprintsandpermissions/

How to cite this article: Wang, H. et al. An ultrafast nickel-iron battery from strongly coupled inorganic nanoparticle/nanocarbon hybrid materials. Nat. Commun. 3:917 doi: 10.1038/ncomms1921 (2012). 